\title{
Structural Performance of FRP Columns with Splice Connection in Modular Buildings
}

\author{
Haleema Nawrin ${ }^{1}$, Binu. $\mathrm{P}^{2}$ \\ ${ }^{1}$ Mtech Student; ${ }^{2}$ Associate Professor \\ Department of Civil Engineering \\ Sree Narayana Gurukulam College of Engineering and Technology, \\ Ernakulam, Kerala.
}

\begin{abstract}
Modular buildings are prefabricated buildings that involves constructing sections away from the building site, then delivering them to the intended site. Different types of materials are used for modular constructions such as wood, fiber reinforced polymer (FRP), concrete, cold form steel etc. Pultruded Fibre Reinforced Polymer (FRP) members are increasingly favoured in civil engineering as they are lightweight and corrosion resistant. However, due to the challenge in connecting them, their application is limited especially in tubular members with closed sections. A splice connection is developed for tubular Fibre Reinforced Polymer (FRP) members and this steel Fibre Reinforced Polymer (FRP) connection system consists of two components which includes a bonded sleeve joint coupling fibre reinforced polymer and steel tubes adhesively, and a bolted flange joint connecting two steel hollow sections through fillet weld. The Bonded Sleeve Joint reduces stress concentration in the fibre reinforced polymer compared to bolt fastening, while the Bolted Flange Joint enables convenient installation and imparts ductility to the system (through steel yielding). Bending performance of this innovative splice connection is evaluated for various sections of columns such as hexagonal, rectangular, square etc with varying bond lengths to find the most effective model.
\end{abstract}

Keywords-Fibre Reinforced Polymer; Tubular members; Splice connection; Moment capacity; Bolted flange joint; Bonded sleeve joint.

\section{INTRODUCTION}

Modular buildings and modular homes are prefabricated buildings or houses that consist of repeated sections called modules. It is a construction method that involves constructing sections away from the building site, then delivering them to the intended site. Modular buildings can be constructed using wood, Fibre Reinforced Polymer (FRP), concrete, cold form steel etc. Fibre Reinforced Polymer (FRP) is a composite material made of polymer matrix reinforced with fibres. The fibres are usually glass (GFRP), carbon (CFRP), aramid or basalt. The polymer is usually an epoxy, vinyl ester, or polyester thermosetting plastic. Application of Fibre Reinforced Polymer (FRP) composites in civil engineering structures has shown an increase in the past two decades. These lightweight and corrosion-proof materials through their applications in the rehabilitation and strengthening of existing structures have attained much recognition worldwide. Glass Fibre Reinforced Polymer (GFRP) composites have been considered as load-carrying structural members in civil engineering because of their light weight, high strength, corrosion resistance, and low maintenance requirements. They are now produced through pultrusion techniques with various structural sections, such as I - shaped and tubular sections, showing great potential for frame and building applications. Such implementations, however, require reliable connection systems between GFRP beams and columns. Glass FRP (GFRP) composites are credited with sufficient strength and stiffness at moderate cost. Due to the advances in the pultrusion manufacturing technique, FRP composites also have great potential as load-bearing members in new construction. Examples include bridge decks, beams, columns, and floor systems. Connection designs for these members should consider the brittle and anisotropic nature of FRP materials. Comparing with open section profiles (I or channel profiles), closed section profiles (circular or rectangular tubular profiles) shows better resistance against torsional and global buckling. Yet these merits of tubular GFRP members coexist with the difficulty of connecting the members into truss and frame assemblies, due to the material anisotropy and the closed section shape [1]. In the development of a connection form for axially loaded tubular FRP profiles, the use of a steel tubular sleeve connector which was inserted into and bolt-fastened to the tubular FRP profile was commonly used. This steel sleeve connector facilitated versatile connection forms to adjacent members. Despite the convenience of in-situ installation, bolt fastening requires hole-drilling on the composite material, creating problems such as damaged fibre architecture, stress concentration, and exposure of the weak in-plane shear strength of the FRP composites [1]. Adhesive bonding, as an alternative, offers structural integrity, reduced stress concentration and also improved fatigue resistance. Combining these benefits of the adhesive bond and the steel sleeve connector, bonded sleeve connections for joining circular GFRP truss members to nodal joints was proposed [1].

Based on further studies on connecting steel tubular members, a splice connection is developed for connecting tubular Fibre Reinforced Polymer (FRP) members (Fig.1) and this steel FRP connection system consists of two components: a Bonded Sleeve Joint (BSJ) coupling FRP and steel tubes adhesively, and a Bolted Flange Joint (BFJ) connecting two steel hollow sections through fillet weld. The BSJ reduces stress concentration in the FRP compared to bolt fastening, while the BFJ enables convenient installation and imparts ductility to the system (through steel yielding) [2]. Splice connection allow connecting two collinear elements using additional plates on webs and/or flanges. 


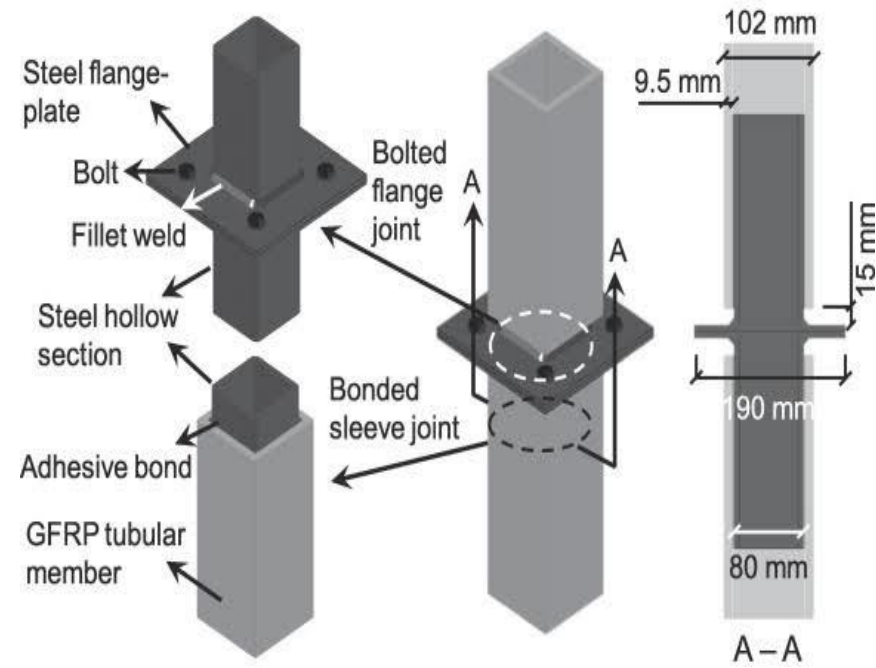

Fig.1. Proposed Splice connection for tubular FRP members.

\section{LITERATURE REVIEW}

All previous studies conducted on splice connected FRP tubular members reveals that these splice connections imparts considerable ductility to a structure made of brittle FRP members and shows improved rotational stiffness and yield moment [1][2]. According to [3] the multi continuum method is practically the best suited method for composite analysis since it gives complete insight about the fibre failure in all the layers of the material. FRP tubular members with bolted sleeve joints under axial loading (tension and compression) shows linear elastic deformation followed by a brittle and catastrophic failure in the case of bolt tension specimens and in the case of compression specimen's linear deformation occurred only to a certain level along with an ultimate loading owing to a bearing failure which was pseudo-ductile failure. Shear-out failure was the ultimate joint failure for all ordinary bolt specimens regardless of loading direction [7]. From the failure modes observed experimentally, it was found specimen with a longer bond length failed initially by yielding of the steel plate whereas specimen with shorter bond length failed initially by cohesive failure. After the yielding of steel plate, transverse compressive failure was observed on the web walls of specimens with longer bond lengths. As per [8], for splice joints transverse stiffness increases linearly as the bolt torque increases. Incorporating two different pultruded directions within one slab structure of FRP shows sufficient mechanical performance under static loading and prevents formation of longitudinal cracking commonly observed in existing FRP structures [1]. According to [9] bolted flange-plate connections in FRP structures shows good yielding capacity for the connections. This connection provides adequate ductility and energy dissipation capacity which is advantageous for seismic applications [4].

\section{NUMERICAL ANALYSIS}

In order to verify the accuracy of a numerical model using finite element software, numerical analysis from a journal is reciprocated using its model dimensions and other input parameters. The details from journal [2] were opted for the validation of mathematical model using the finite element software ANSYS 16.1.The model named as B-170-4 was taken for validation purpose where B stands for bending loading; 170 is the bond length/splice length of the steel-FRP bonded sleeve joint in $\mathrm{mm}$; and 8 is the number of bolts used. A grade 355 steel square tube of size $80 \times 80 \times 6 \mathrm{~mm}$ was joined to a $6 \mathrm{~mm}$ thick grade 250 steel flange plate by fillet welds with a leg length of $6 \mathrm{~mm}$ approximately. The other end of the steel tube was coaxially coupled into and bonded to a pultruded glass fibre reinforced polymer square tube of size $102 \times 102 \times 9.5$ $\mathrm{mm}$. Two of the bonded assemblies are fastened together at the steel flange-plate with 8.8 bolts having M12 grade. GFRP material has a Transverse flexural strength of $88.5 \mathrm{MPa}$; Young's modulus as $25200 \mathrm{MPa}$; and Poisson's ratio as 0.3. While steel flange plate has Yield strength of $311.8 \mathrm{MPa}$; Young's modulus of $2.01 \times 10^{5} \mathrm{MPa}$; and Poisson's ratio as 0.3.Steel square tube has yield strength of $420.1 \mathrm{MPa}$; Young's modulus of $2.09 \times 10^{5} \mathrm{MPa}$; and Poisson's ratio as 0.3. 8.8 bolts have yield strength of $640 \mathrm{MPa}$; Young's modulus as $2.01 \times 10^{5} \mathrm{MPa}$; and Poisson's ratio as 0.3. After proper modelling and meshing of B-170-8, the model is analysed under push over analysis. The maximum bending moment corresponding to the maximum displacement obtained from the validation is $9.2 \mathrm{kNm}$ while the maximum bending moment obtained from the journal is $9 \mathrm{kNm}$. Therefore the percentage error obtained is less than $5 \%$.

Parametric study on splice connected FRP tubular column using pushover analysis to find the best model having better stiffness and load carrying capacity is aimed in this study.

\section{MODELLING OF FRP COLUMN}

Numerical modeling of the splice connected FRP columns performed by the finite element software ANSYS 19 WORKBENCH. Various sections of columns are considered for the analysis such as square, rectangle and hexagonal FRP columns each of these sections having splice length $170 \mathrm{~mm}$, $150 \mathrm{~mm}, 190 \mathrm{~mm}$ simultaneously. A square FRP column with an $\mathrm{L}$ stiffener is also introduced in order to improve the flange strength. The FRP square column is of size $102 \times 102 \times 9.5$ $\mathrm{mm}$, rectangle is of size $92 \times 112 \times 9.5 \mathrm{~mm}$ and hexagonal column is of size $63.28 \times 9.5 \mathrm{~mm}$. The model's material property was chosen from the engineering data section of the ANSYS software. This data section consists of pre-assigned values for each material. Poisson's ratio and density used for each material is 0.3 and $7850 \mathrm{~kg} / \mathrm{m}^{3}$ respectively. Sikadur-330 adhesive was used as the epoxy material. The material properties given for the model is shown in the below tables.

TABLE I. MATERIAL PROPERTIES OF STEEL SQUARE TUBE

\begin{tabular}{|l|c|}
\hline \multicolumn{1}{|c|}{ Item } & Steel Square tube \\
\hline Modulus of elasticity & $2 \times 10^{5} \mathrm{~N} / \mathrm{mm}^{2}$ \\
\hline Yield strength & $415 \mathrm{MPa}$ \\
\hline
\end{tabular}

TABLE II. MATERIAL PROPERTIES OF GFRP MATERIAL

\begin{tabular}{|l|c|}
\hline \multicolumn{1}{|c|}{ Item } & GFRP Material \\
\hline Modulus of elasticity & X direction: $25200 \mathrm{MPa}$ \\
& Y direction: $6200 \mathrm{MPa}$ \\
& Z direction: $6200 \mathrm{MPa}$ \\
\hline Yield strength & $330 \mathrm{MPa}$ \\
\hline
\end{tabular}


TABLE III. MATERIAL PROPERTIES OF FLANGE PLATE

\begin{tabular}{|l|c|}
\hline \multicolumn{1}{|c|}{ Item } & Steel Flange Plate \\
\hline Modulus of elasticity & $2 \times 10^{5} \mathrm{~N} / \mathrm{mm}^{2}$ \\
\hline Yield strength & $311 \mathrm{MPa}$ \\
\hline
\end{tabular}

TABLE IV. MATERIAL PROPERTIES OF EPOXY

\begin{tabular}{|l|c|}
\hline \multicolumn{1}{|c|}{ Item } & Epoxy \\
\hline Modulus of elasticity & $4500 \mathrm{GPa}$ \\
\hline Yield strength & $32.2 \mathrm{MPa}$ \\
\hline
\end{tabular}

TABLE V. MATERIAL PROPERTIES OF 8.8 BOLT

\begin{tabular}{|l|c|}
\hline \multicolumn{1}{|c|}{ Item } & $\mathbf{8 . 8}$ bolt \\
\hline Modulus of elasticity & $2 \times 10^{5} \mathrm{~N} / \mathrm{mm}^{2}$ \\
\hline Yield strength & $1043 \mathrm{MPa}$ \\
\hline
\end{tabular}

In this analysis FRP tubular columns in various sections and dimensions which are connected by using splice connection are considered. In each model a steel tube will be joined to a steel flange plate by using fillet welds. The other end of the steel tube will be coaxially coupled into and bonded to a pultruded glass fiber reinforced polymer (GFRP) square tube with Sikadur-330, a two-component epoxy based adhesive. So in this connection system a bonded sleeve joint (BSJ) is coupling GFRP and steel tubes adhesively and a bolted flange joint (BFJ) is connecting two steel hollow sections through fillet weld. The modeling is done using ANSYS 19 WORKBENCH. Comparison study of square, rectangular and hexagonal tubular columns each having bond lengths $170 \mathrm{~mm}$, $150 \mathrm{~mm}$ and $190 \mathrm{~mm}$ is conducted here. Flange thickness is $6 \mathrm{~mm}$. FRP column length is $890 \mathrm{~mm}$. Number of bolts used is 8.

This parametric study is conducted to bring out the best model with a suitable section and splice length. This involves study of splice connected square FRP tubular columns having varying sections with different bond lengths. As mentioned earlier the sections considered for the study includes square, rectangle and hexagonal columns having depth of $890 \mathrm{~mm}$. Various bond lengths considered for the study are 170, 150 and 190. Deformation and stiffness of the models are determined and compared. Out of these the best model having better stiffness and load carrying capacity is selected as effective and is used for further analysis. The engineering data section of the software consists of pre-assigned values for each material.

The models used in the FRP column splice connection parametric study are S-170-8, REC-170-8, HEX-170-8, S-1708-Stiffener, S-150-8, REC-150-8, HEX-150-8, S-150-8, S-1908, REC-190-8, HEX-190-8 which is in the form B-X-y where B is the column section, $\mathrm{x}$ is the splice length and $\mathrm{y}$ is the number of bolts. In S-170-8-Stiffener, an additional L-stiffener is used. This will helps to improve the flange strength. Fig.2 shows the splice connected FRP column (S-170-8).

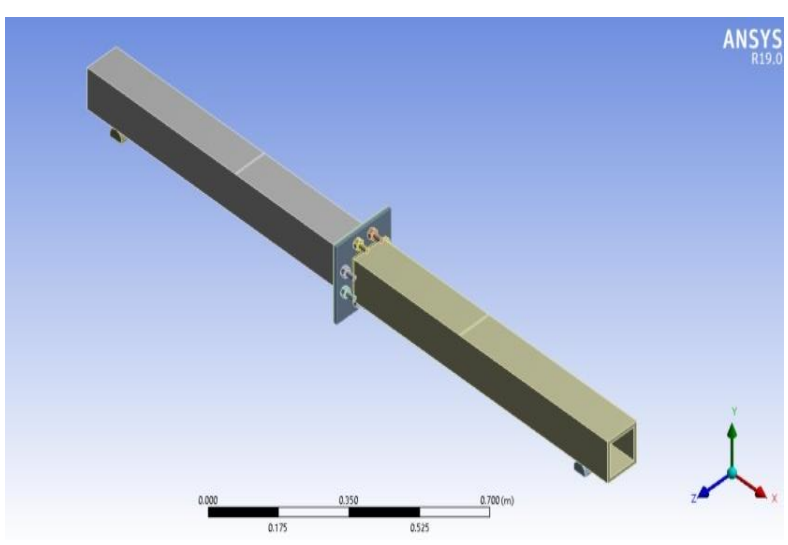

Fig.2. Splice connected Square FRP column (S-170-8)

\section{A. Support and Loading conditions}

Support and loading was given to each models after modeling. Fixed support was given at a distance of $0.42 \mathrm{~m}$ from the ends of the two connected columns and a loading was given at a distance of $0.12 \mathrm{~m}$ from the connection to both the columns.

\section{RESULTS AND DISCUSSIONS}

\section{A. Static Analysis}

From the analysis, an equivalent plastic strain was observed in each model. Fig.3 shows the equivalent plastic strain distribution in HEX-170-8 model. The plastic strain observed is mainly concentrated in the flange plate region of splice connection and thereby creating the plastic deformation in face of the connection plate.

\section{B. Comparison study}

In this objective, a comparative study is done in order to find out the most effective model based on varying sections and splice length by push-over analysis. The square, rectangular and hexagonal models each having splice length $170 \mathrm{~mm}, 150 \mathrm{~mm}, 190 \mathrm{~mm}$ and model with an L-stiffener is compared based on their load carrying capacity and deformation.

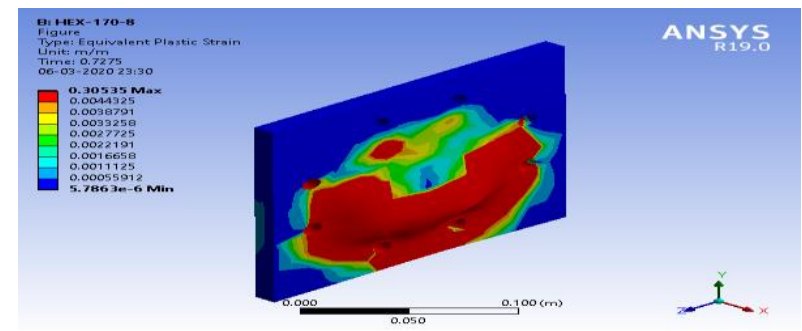

Fig.3. Equivalent plastic strain of HEX-170-8

TABLE VI. COMPARISON OF RESULTS

\begin{tabular}{|l|l|l|l|}
\hline $\begin{array}{l}\text { SPLICE } \\
\text { LENGTH }\end{array}$ & SECTION & $\begin{array}{l}\text { MOMENT } \\
(\mathbf{k N m})\end{array}$ & $\begin{array}{l}\text { DEFORMATION } \\
(\mathbf{m})\end{array}$ \\
\hline $170-8$ & Square & 15.887 & 0.15499 \\
\hline $170-8$ & Square-stiffener & 17.726 & 0.14618 \\
\hline $170-8$ & Rectangle & 21.919 & 0.13799 \\
\hline $170-8$ & Hexagon & 15.685 & 0.17921 \\
\hline $150-8$ & Square & 15.283 & 0.15793 \\
\hline $150-8$ & Rectangle & 21.659 & 0.12072 \\
\hline $150-8$ & Hexagon & 15.549 & 0.17258 \\
\hline
\end{tabular}




\begin{tabular}{|l|l|l|l|}
\hline $190-8$ & Square & 16.085 & 0.15751 \\
\hline $190-8$ & Rectangle & 21.889 & 0.16508 \\
\hline $190-8$ & Hexagon & 15.784 & 0.17258 \\
\hline
\end{tabular}

The models having splice length $170 \mathrm{~mm}$ and $150 \mathrm{~mm}$ shows better stiffness and load carrying capacity while models having splice length $190 \mathrm{~mm}$ failed up taking lesser load compared to models having splice length $170 \mathrm{~mm}$ and $150 \mathrm{~mm}$. Out of this S-170-8 and HEX-170-8 has almost equal moments and load carrying capacity. But in the case of hexagonal columns deformation is larger compared to other columns hence rotation angle will increase. In rectangular sections, moment is larger while deformation is varying much larger while increasing the splice length and width. This makes it less effective compared to other sections. From all these results it is concluded that square sections having $170 \mathrm{~mm}$ bond length is much effective in stiffness and load carrying capacity. Out of this, square section having an L-stiffener will helps to improve the flange strength thereby failure at flanges can be reduced. Comparing with S-170-8 it has larger moment. Hence S-170-8Stiffener is used as the best model applicable to building frames as per ASTM Standards.

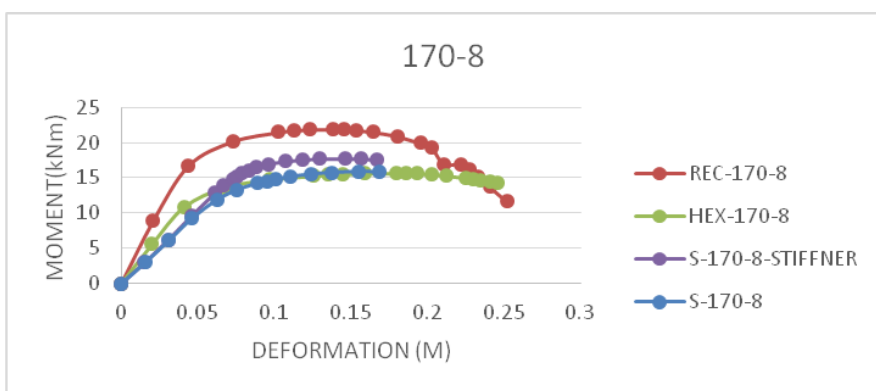

Fig.4. Comparison of Moment-deformation curve having splice length $170 \mathrm{~mm}$

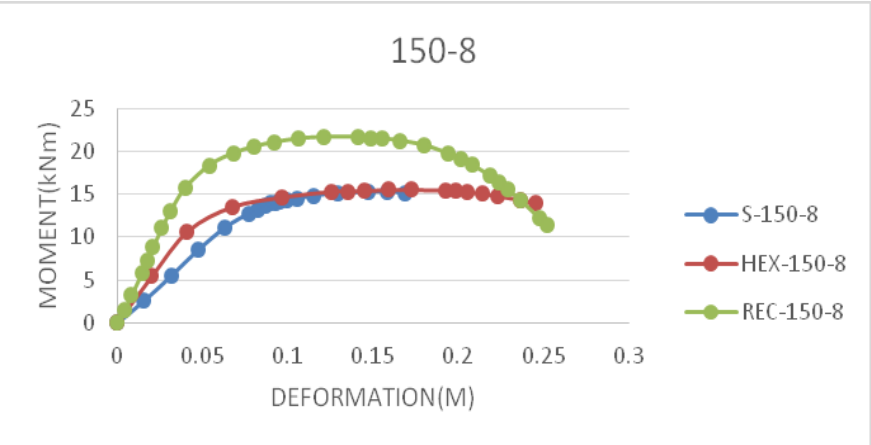

Fig.4. Comparison of Moment-deformation curve having splice length $150 \mathrm{~mm}$

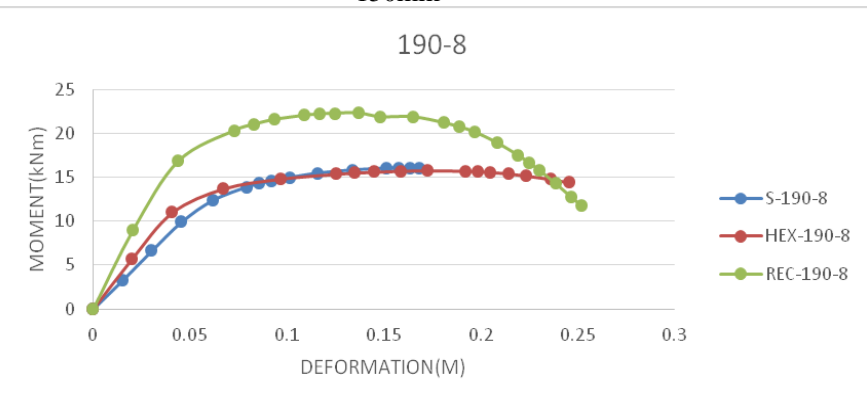

Fig.4. Comparison of Moment-deformation curve having splice length 190mm

\section{CONCLUSION}

This paper investigated the comparative study of splice connected FRP tubular columns having sections such as square, rectangle and hexagon each having varying bond lengths $(150 \mathrm{~mm}, 170 \mathrm{~mm}, 190 \mathrm{~mm})$ in order to find the best model applicable to building frames as per ASTM standards. Based on the results from Finite Element modeling it is concluded that splice connected square tubular column having splice length $170 \mathrm{~mm}$ with the use of an L-stiffener (S-170-8Stiffener) gives better results in moment capacity and stiffness. It also imparts strength to the flange plate thereby reduces flange failure.

\section{REFERENCES}

[1] Chengyu Qiu, Chenting Ding, Xuhui He, Lei Zhang and Yu Bai, “Axial Performance of Steel Spliced Connection for Tubular FRP Column Members", Composite Structures, ELSEVIER, Vol. 25, pp. 498-509, February 2018.

[2] Chengyu Qiu, Yu Bai, Lei Zhang and Li Jin, "Bending Performance of Splice Connections for Assembly of Tubular Section FRP Members: Experimental and Numerical Study", Journal of Composite Structures, ASCE, Vol.23, pp. 55-70, 2019.

[3] Emayavaramban.E and Pravin Raj E.L, "Finite Element Analysis of Different Composite Materials using Multi Continuum Method", Journal of Mechanical and Civil Engineering, IOSR, Vol. 11, pp. 94-99, March 2014.

[4] En-Feng Denga, Liang Zonga, Yang Dinga, Xiao-Meng Daia, Ni Louc and Yang Chend, "Monotonic and Cyclic Response of Bolted Connections with Welded Cover Plate for Modular Steel Construction", Engineering Structures, ELSEVIER, Vol. 17, pp. 407-419, 2018.

[5] F. Ascione, M. Lamberti, A.G. Razaqpur and S. Spadeav, "Strength and Stiffness of Adhesively Bonded GFRP Beam-Column Moment Resisting Connections", Composite Structures, ELSEVIER, Vol. 5, pp. 1-10, November 2016

[6] F. Ascione, M. Lamberti, A.G. Razaqpur and S. Spadeav, "Pseudo Ductile Failure of Adhesively Joined GFRP Beam-Column Connections: An Experimental and Numerical Investigation", Composite Structures, ELSEVIER, Vol. 20, pp. 864-873, 2018.

[7] Fu Jia Luo, Yu Bai, Xiao Yang, and Ye Lu, "Bolted Sleeve Joints for Connecting Pultruded FRP Tubular Components", Journal of Composite Structures, ASCE, Vol. 20, pp. 1-11, 2016.

[8] Geoffrey John Turvey and Xavier Cerutti, "Flexural Behaviour of Pultruded Glass Fibre Reinforced Polymer Composite Beams with Bolted Splice Joints", Composite Structures, ELSEVIER, Vol. 119, pp. 543-550, September 2015

[9] Juan E. Carrion, Keith D. Hjelmstad and James M. LaFave, "Finite Element Study of Composite Cuff Connections for Pultruded Box Sections", Composite Structures, ELSEVIER, Vol. 70, pp. 153-169, September 2004.

[10] Sindu Satasivam, Yu Bai and Xiao-Ling Zhao, "Adhesively Bonded Modular GFRP Web-Flange Sandwich for Building Floor Construction", Composite Structures, ELSEVIER, Vol. 11, pp. 381-392, 2014 . 